\title{
Room-Temperature Creep Resistance of Co-Based Metallic Glasses
}

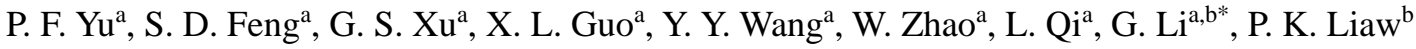 \\ and R. P. Liu $^{\mathrm{a}}$ \\ ${ }^{1}$ State Key Laboratory of Metastable Materials Science and Technology, Yanshan \\ University, Qinhuangdao 066004, China \\ ${ }^{2}$ Department of Materials Science and Engineering, The University of Tennessee, \\ Knoxville, TN 37996-220 0, USA \\ *E-mail address: gli25@utk.edu, gongli@ysu.edu.cn (Gong Li) Tel. \& Fax: +86 335 \\ 8074545 .
}

\begin{abstract}
The room-temperature creep resistance of the $\mathrm{Co}_{56} \mathrm{Ta}_{9} \mathrm{~B}_{35}$ metallic glass was determined by a nanoindentation technique. Results showed that the creep curves were described by a generalized Kelvin model. The low creep strain-rate sensitivity parameter and creep rate derived from the displacement-holding time curves demonstrated the high creep resistance of the $\mathrm{Co}_{56} \mathrm{Ta}_{9} \mathrm{~B}_{35}$ metallic glass. The deformation mechanism causing the nanoindentation creep was discussed based on the "shear transformation zone" concept, which gave an explanation for the creep behavior in metallic glasses.
\end{abstract}

Keywords: Metallic glasses; Nanoindentation; Creep resistance; Shear transformation zone 
A number of Co-based multicomponent metallic glass (MG) systems have been reported, including $\mathrm{Co}-\mathrm{Fe}-(\mathrm{Ta}, \mathrm{Mo})-(\mathrm{B}, \mathrm{Si})$ [1-4], (Co-Fe)-(Nb,Zr)-(B,Si) [5-9], (Co,Fe,Ni)-(Zr,Hf,Nb,Ta,Mo,W)-B [10], and Co-Fe-B-Si [11]. Since then, the family of Co-based MGs has been widely studied in recent decades. A wide range of material properties have been investigated, including the glass-forming ability [7-9], thermal stability, strength [1-3,8], and magnetic properties [2,7,9-11]. For instance, the $\mathrm{C}_{43} \mathrm{Fe}_{20} \mathrm{Ta}_{5.5} \mathrm{~B}_{31.5} \mathrm{MG}$ has been reported as the strongest MG [2] with promising magnetic applications $[1,2,4,12-14]$. The tensile strengths of $\mathrm{Co}-\mathrm{Si}-\mathrm{B}$ and $\mathrm{Co}-\mathrm{Ta}-\mathrm{Si}-\mathrm{B}$ alloys have been reported to range from 3,580 $\mathrm{MPa}$ and 4,000 $\mathrm{MPa}$, respectively. When $\mathrm{Fe}$ is removed from the Co-Fe-Ta-B ribbon and wire MGs [12], the fracture strength of Co-based MGs can even increase to above 6,000 MPa.

Co65-x $\operatorname{Ta}_{x} B_{35}($ at. $\%, x=5-11)[12,15]$ systems have rapidly been of broad interest, which set the record for the highest strength among the known bulk glassy alloys, which elastic moduli and hardness are 280 , and $17.8 \mathrm{GPa}$, respectively. Our recent research $[15,16]$ on the compressibility of CoTaB MGs under high pressures by using synchrotron radiation X-ray diffraction confirmed that the charge density and bonding character demonstrates that the covalent character of Co-B and B-B bonds is the reason of the high elastic modulus and hardness in CoTaB MGs [15].

Very recently, a plasticity ternary $\mathrm{C}_{61} \mathrm{Nb}_{8} \mathrm{~B}_{31}$ bulk MG with plasticity of $5 \%$ and yield strength of 5,200 MPa was fabricated [17]. However, the room-temperature creep-resistance behavior of Co-based MGs has not been reported. The plastic deformation of MGs and the related mechanism are considered as one of the most 
important aspects of their engineering application. Thus, studying the creep-resistance behavior of materials can enable the selection of appropriate materials in different environments. Given the size limitation of MGs, many mechanical properties cannot be studied by traditional methods. A new nanoindentation technique has recently paved a new path for research on the plastic deformation of glassy alloys [18]. Therefore, in this work, we use $\mathrm{Co}_{66} \mathrm{Ta}_{9} \mathrm{~B}_{35}$ as a model MG to study the creep-resistance behavior at room temperature using the nanoindentation technique.

The amorphous ribbon was prepared by the melt-spinning technique in an argon atmosphere. The glassy structure of the alloys was ascertained by X-ray diffraction (XRD) using a D/MAX-2500/PC diffractometer with the $\mathrm{Cu}$ Ka radiation $(\lambda=1.54 \AA)$. The thermal stability of ribbons was determined using a NETZSCH STA449C differential scanning calorimetry (DSC) device at a heating rate of 20 $\mathrm{K} / \mathrm{min}$. Nano-indentation experiments were conducted on a nanoindenter Hysitron TriboIndenter with a diamond Berkovich tip having a $260 \mathrm{~nm}$ radius of curvature. Hardness and Young's modulus were investigated according to the analysis of Oliver and Pharr [19]. Creep measurements were performed as follows. The load was increased up to the maximum load, $P_{\max }$, of $4,000 \mu \mathrm{N}$ at different loading rates, $\mathrm{d} P / \mathrm{d} t$, of 40,100 , and $400 \mu \mathrm{N} / \mathrm{s}$. The indenter was held at $P_{\max }$ for $60 \mathrm{~s}$ to measure the time-dependent displacement, and the unloading kept the same rate as the loading rate. The indenter was then unloaded to $10 \%$ of the maximum load and held for the thermal drift correction. The data were averaged in groups of five.

Figure 1 (a) shows the XRD pattern of the amorphous ribbon. The broad 
diffraction maxima and absence of Bragg peaks corresponding to the crystalline phase in the XRD curves are characteristic of an amorphous structure.

Based on the DSC trace in Fig. 1 (b), the glass-transition temperature $\left(T_{\mathrm{g}}\right)$, crystallization temperature $\left(T_{\mathrm{x}}\right)$, crystallization peak temperature $\left(T_{\mathrm{p}}\right)$, and supercooled liquid region, $\Delta T_{\mathrm{x}},\left(\Delta T_{\mathrm{x}}=T_{\mathrm{x}}-T_{\mathrm{g}}\right)$ were determined to be $964.5,1,014$, 1,023, and $49.5 \mathrm{~K}$, respectively. The $\mathrm{Co}_{56} \mathrm{Ta}_{9} \mathrm{~B}_{35} \mathrm{MGs}$ exhibited both the high glass-transition temperature and large super-cooled liquid region, which are markedly favorable for the extensive application of MGs as structural materials because of their high thermal stability.

Figure 2 presents load-displacement $(P-h)$ nanoindentation curves obtained under load control mode for the different loading rates, of 40,100 , and $400 \mu \mathrm{N} / \mathrm{s}$. The apparent absence of serrations at low depths $(60 \mathrm{~nm})$ may be the reason of either lack of resolution of the system or the fully elastic response of the material in the first nanometers of penetration. Pop-in events appear in the low loading curves obviously, but they become imperceptible at the high loading rate. The creep platforms appear at different loading rates. While, larger displacements are observed for higher loading rates ( $3 \mathrm{~nm}$ for $400 \mu \mathrm{N} / \mathrm{s}$ ), suggesting that, for high rates, the plastic flow, which was not produced during the loading stage, occurs during the force holding stage.

Figure 3 shows the experimental data of $\mathrm{Co}_{56} \mathrm{Ta}_{9} \mathrm{~B}_{35} \mathrm{MG}$ with the creep at 4,000 $\mu \mathrm{N}$. The indenter displacement rapidly increased at the beginning of the holding period and then approached a steady state at the end of the creep curve. The results 
showed that a faster strain rate resulted in the larger creep displacement. The creep displacement $(h)$ and creep rate $\left(\varepsilon_{s}=\frac{d h}{d t}\right)$ of $\mathrm{Co5}_{6} \mathrm{Ta}_{9} \mathrm{~B}_{35}$ can be obtained from Fig. 3 and are summarized in Table 1.

Viscoelastic (anelastic and viscoplastic) deformation can generally be described as a series of linear springs and dashpots, known as the Kelvin model. This model is commonly used to describe the creep of polymers [20-22] but can also be used for MGs (e.g., [23]), i.e.,

$$
\mathrm{h}=\sum_{i=1}^{n} h_{i}\left(1-\mathrm{e}^{-\frac{t}{\tau_{i}}}\right)+\frac{t}{\mu_{0}}
$$

where $h_{i}$ is the indentation depth and $\tau_{i}$ is the characteristic relaxation time for the activation of the $i$ th anelastic process. In the second term on the right-hand side of Equation (1), $t$ is the experimental time, and $\mu_{0}$ is a constant proportional to the viscosity coefficient of the last dashpot.

The creep curves in Fig. 3 are successfully fitted by a series of two exponential decays representing the anelastic deformation plus the viscoplastic contribution, $t / \mu_{0}$. Notably, Fig. 3 shows that for a typical displacement-holding time curve. Equation (1) can simulate the experimentally-measured creep rate of the present MG with high accuracy (correlation coefficient $R^{2}>0.98$ for all tests).

In the present work, different loading rates cause various creep displacements, which indicate that the material undergoes various processes. When the indenter presses into the material, elastic deformation initially occurs, and then the process enters the stage in which elastic deformation and plastic deformation co-exist. Finally, the process completely becomes plastic deformation. In the amorphous ribbon, elastic 
deformation spreads faster than the plastic deformation. When the ribbon is subjected to high loading rates, the production of plastic deformation may be too late for some parts. Residual plastic deformation around the indenter is then released during the holding time stage, resulting in more serious creep displacement than others. However, during the low load rates, plastic deformation can be completely released, thereby yielding small values. Another explanation for the observed rate dependency can be offered from earlier studies wherein it has been observed that faster rate of loading induces a higher energy state [24,25]. For example, de Hey et al. [26] showed that faster loading leads to a higher production rate of excess free volume (and thus more shear transformation zones). Note that, at a steady state, plasticity in MGs is a balance between the free-volumes creation and annihilation [25]. Therefore, more free volume created during the higher loading rate is in beneficial to visco-plastic deformation during the hold period, which results in larger displacements (Fig. 3).

To gain more information on the creep-resistance behavior of MGs, we calculated the creep-strain-rate-sensitivity-parameter $(m)$.

The nanoscale creep curves can be described by the following equation [27]:

$$
\dot{\varepsilon}=a \sigma^{\frac{1}{m}} \exp (-Q / R T)
$$

where $\dot{\varepsilon}$ and $\sigma$ represent strain rate and stress, respectively; $a$ is constant; $Q$ represents the activation energy; and $m$ is the creep-strain-rate-sensitivity-parameter. Following the earlier investigators [28], the relationship between the strain rate and hardness $(H)$ gradient can be determined as

$$
\dot{\varepsilon}=-\beta \frac{1}{H} \frac{d H}{d t}
$$


where $\beta$ represents a constant and the relation between stress $(\sigma)$ and hardness $(H)$ could be described as

$$
H=C \sigma
$$

where $C$ is a constant. Substituting Eqs. (3) and (4) into Eq. (2) and integrating the two sides of $\boldsymbol{t}$, the relationship between the hardness of creep and the holding time is presented as follows:

$$
-\frac{1}{m} \ln H=\ln B-Q / R T+\ln t
$$

Then, $\ln H$ is taken as the vertical ordinate and $\ln t$ as the horizontal ordinate, as demonstrated in Fig. 4. From which we can derive the values of $m$, i.e., $5.439 \times 10^{-4}$, $6.752 \times 10^{-4}$, and $7.676 \times 10^{-4}$ for the loading rate of 40,100 , and $400 \mu \mathrm{N} / \mathrm{s}$, respectively. If $m=1$, the flow is Newtonian; $\mathrm{m}<1$ indicates the inhomogeneous non-Newtonian flow. This quite low $m$ values in the present MG is attributed to the strongly localized shear flow.

The relatively low $m$ and creep rate (Table 1 ) indicate the high creep resistance of the present MG. According to empirical records, the values of $m$ exhibit a three or four orders of lower than crystalline metal structural materials. For example, it is $0.018 \sim 0.058$ for $\mathrm{Ni}$ and Ni-based alloys [29]. And the values of $m$ of the present Co-based MG are lower than other MGs, $0.00339,0.0043$ and 0.00582 at loading rates of $6 \mathrm{mN} / \mathrm{s}, 10 \mathrm{mN} / \mathrm{s}$, and $10 \mathrm{mN} / \mathrm{s}$ for Fe-based MG [30]. The creep rate is lower than most MGs, such as Ce-based MGs, the creep rate are 0.039, and 0.080 $\mathrm{nm} / \mathrm{s}$ for $\mathrm{Ce}_{60} \mathrm{Al}_{15} \mathrm{Ni}_{15} \mathrm{Cu}_{10}$ and $\mathrm{Ce}_{68} \mathrm{Al}_{10} \mathrm{Cu}_{20} \mathrm{Nb}_{2} \mathrm{MGs}$, respectively [31]. The reasons can be analyzed based on two aspects. In the macroscopic aspect, creep properties 
are correlated with the hardness and elastic modulus of materials. High hardness and elastic modulus generally indicate the high atomic-bonding energy [16], which makes the atomic diffusion difficult. Nanoindentation experiments have shown that $\mathrm{Co5}_{6} \mathrm{Ta}_{9} \mathrm{~B}_{35}$ has the high hardness $19.04 \mathrm{GPa}$ and elastic modulus 219.15 GPa.

In the microscopic aspect, creep properties are strongly related to the localized shear flow. Jiang et al. [32] found that the density of low-density defects, such as nanovoids resulting from the coalescence of excess free volumes, is higher in the shear band than in the undeformed region. According to the free-volume theory [33-35], free volumes primarily increase under a certain stress for MGs, and some atomic-scale localized shear flows and shear bands originate from the concentration of free volumes. However, if some heterogeneous short-range ordered structures exist in the alloy (e.g., short chemical ordering or so-called topological ordering [37]) the distribution of free volumes changes, and localized shear flows are prevented. This phenomenon results in the formation of more inhomogeneous complex zones that can block localized shear flows and increase the deformation resistance of creep. Therefore, the shear bands in amorphous alloys and the unusually high elastic modulus and hardness in this material play an important role that leads to high creep resistance.

In this paper, we investigated the room-temperature creep-resistance behavior of the Co56Ta9B 35 MG. Creep curves were described by the Kelvin model. The creep strain-rate-sensitivity parameter of the $\mathrm{Co}_{6} \mathrm{Ta}_{9} \mathrm{~B}_{35} \mathrm{MG}$ was significantly smaller than that of crystal metal structural materials, including MGs. The observation indicated 
the excellent creep resistance of the $\operatorname{Cos}_{6} \mathrm{Ta}_{9} \mathrm{~B}_{35} \mathrm{MG}$ and the potential of this Co-based MG as an engineering material. The results on the $\mathrm{Co}_{56} \mathrm{Ta}_{9} \mathrm{~B}_{35} \mathrm{MG}$ can guide other researchers in future investigations on Co-based MGs.

\section{Acknowledgments}

The research was supported by the National Science Foundation of China (Grant No. 51121061/51171163). Peter K. Liaw would like to acknowledge the U.S. Army Research Office project (W911NF-13-1-0438) with the program manager, S. N. Mathaudhu, and the DOE, Office of Fossil Energy, National Energy Technology Laboratory (DE-FE-0008855 and DE-FE-0011194), with Mr. V. Cedro and Dr. S. Markovich as program managers, respectively. 


\section{References}

[1] A. Inoue, B. L. Shen, C. T. Chang, Intermetallics, 14 (2006) 936-944.

[2] A. Inoue, B. Shen, H. Koshiba, H. Kato, A. R. Yavari, Nature Mater., 2 (2003) 661-663.

[3] B. Shen, A. Inoue: J. Phy.: Condensed Matter., 17 (2005) 5647-5653.

[4] P. Sharma, H. Kimura, A. Inoue, J. Appl. Phys. 100 (2006) 083902-1-083902-10.

[5] A. Inoue, H. Koshiba, T. Itoi, A. Makino, Appl. Phys. Lett. 73 (1998) 744-746.

[6] J. Fornell, S. Gonzalez, E. Rossinyol, S. Surinach, M. D. Baro, D. V. Louzguine Luzgin, J. H. Perepezko, J. Sort, A. Inoue, Acta Mater.,58 (2010) 6256-6266.

[7] Q. K. Man, H.J. Sun, Y.Q. Dong, B. L. Shen, H. Kimura, A. Makino, A. Inoue, Intermetallics, 18 (2010) 1876-1879.

[8] Z. Y. Chang, X. M. Huang, L. Y. Chen, M. Y. Ge, Q. K. Jiang, X. P. Nie, J. Z. Jiang Mater. Sci. Eng. A, 517 (2009) 246-249.

[9] S. Huaijun, M. Qikui, D. Yaqian, S. Baolong, H. Kimura, A. Makino, A. Inoue, J. Appl. Phys., 107 (2010) 09A319-342.

[10] A. Inoue, T. Zhang, H. Koshiba, A. Makino, J. Appl. Phys., 83 (1998) 6326-6328

[11] I. C. Rho, C. S. Yoon, C. K. Kim, T. Y. Byun, K. S. Hong, J. Non-Cryst. Solids, 316 (2003) 289-296.

[12] J. F. Wang, R. Li, N. B. Hua, T. Zhang, J. Mater. Res., 26 (2011) 2072-2075.

[13] J. H. Yao, J. Q. Wang, Y. Li, Appl. Phys. Lett., 92 (2008) 251906-251908.

[14] C. Hostert, D. Music, J. Bdnarcik, J. Keches, J. M. Schneider, J. Phy.: Con. Matter., 
24 (2012) 175402-1-9.

[15] J. F. Wang, R. Li, R. J. Xiao, T. Xu, Y. Li, Z. Q. Liu, L. Huang, N. B. Hua, G. Li, Y. C. Li, T. Zhang, Appl. Phys. Lett., 99 (2011) 151911-1-1519113.

[16] G. Li, Y. Y. Wang, P. K. Liaw, Y. C. Li, R. P. Liu, Phys. Rev. Lett., 109 (2012) 125501-125505.

[17] C. Dun, H. Liu, L. Hou, L. Xue, L. Dou, W. Yang, Y. Zhao, B. Shen, J. Non-Cryst. Solids, 386 (2014) 121-123.

[18] Q. K Jiang, X. P. Nie, J. Z. Jiang, H. J. Deyneka-Dupriez N Fecht, Scripta Mater., 57 (2007) 149-152.

[19] W. C. Oliver, G. M. Pharr, J. Mater. Res.,7 (1992) 1564-1583.

[20] L. C. Zhang, B. C. Wei, D. M. Xing, T. H. Zhang, W. H. Li, Y. Liu, Intermetallics, 15 ( 2007) 791-795.

[21] Concustell A, Sort J, Alcala' G, Mato S, Gebert A, Eckert J, J. Mater. Res., 20 (2005) 2719-2023.

[22] J. D Ferry, 3rd ed. New York, 1980, John Wiley \& Sons.

[23] A. Castellero, Acta Mater., 56 (2008) 3777-3785.

[24] A.S. Argon, Acta Metall., 27 (1979) 47-58.

[25] F. Spaepen: Acta Metall., 25 (1977) 407-415.

[26] P. de Hey, J. Sietsma, A. Van Den Beukel, Acta Mater., 46 (1998,) 5873-5882.

[27] V. Raman, P. Berriche, J. Mater. Sci., 7 (1992) 627-638.

[28] M. J. Mayo, W. D. Nix, Strength of Metals and Alloys, edited by P. O. Kettunen, T. K. Lepisto, and M. E. Lehtonen (Pergamon, Oxford,1988), p. 1415. 
[29] Y. Gao, S. P. Sheng, X. H. Wang, F. Pan, J. Aeronautical Mater. 26 (2006) 149-152.

[30] J. Peng, Z. L. Long, H. Q. Wei, X. A. Li, Z. C. Zhang, Acta Phy. Sinica, 58 (2009) 4059-4062.

[31] B. C. Wei, T. H. Zhang, W. H. Li, D. M. Xing, L. C. Zhang, Y. R. Wang, Mater. Trans., 46 (2005) 2959-2962.

[32] W. H. Jiang, M. Atzmon, Scripta Mater., 54 (2006) 333-336.

[33] C. A. Pampillo, Scripta Metall. Mater., 6 (1972) 915-918.

[34] D. E. Polk, D. Turnbull, Acta Metall. Sinica, 20 (1972) 493-496.

[35] B. P. Kanungo, S. C. Glade, P. Asoka-Kumar, K. M. Flores, Intermetallics, 12 (2004) 1073-1080.

[36] J. S. Kirkaldy, Mater. Sci. Eng. A, 409 (2005) 167-171. 


\section{FIGURE CAPTIONS}

Fig. 1. XRD pattern (a) and DSC trace (b) of the Co56Ta9B 35 MG, the glass-transition temperature $\left(T_{\mathrm{g}}\right)$, crystallization temperature $\left(T_{\mathrm{x}}\right)$, and crystallization peak temperature $\left(T_{\mathrm{p}}\right)$ indicated in it.

Fig. 2. Load-displacement $(P-h)$ curves measured during nano-indentation tests in load control mode, at different loading rates: 40, 100, and $400 \mu \mathrm{N} / \mathrm{s}$.

Fig. 3. Creep displacement versus time of the $\mathrm{Co}_{56} \mathrm{Ta}_{9} \mathrm{~B}_{35} \mathrm{MG}$ at different loading rates and red solid lines are curve-fitting results.

Fig. 4. Double-logarithmic relationship between the hardness and time for the Co56Ta9B 35 MG under different load rates $(\mu \mathrm{N} / \mathrm{s}$ ): (a) 40, (b) 100, and (c) 400. 

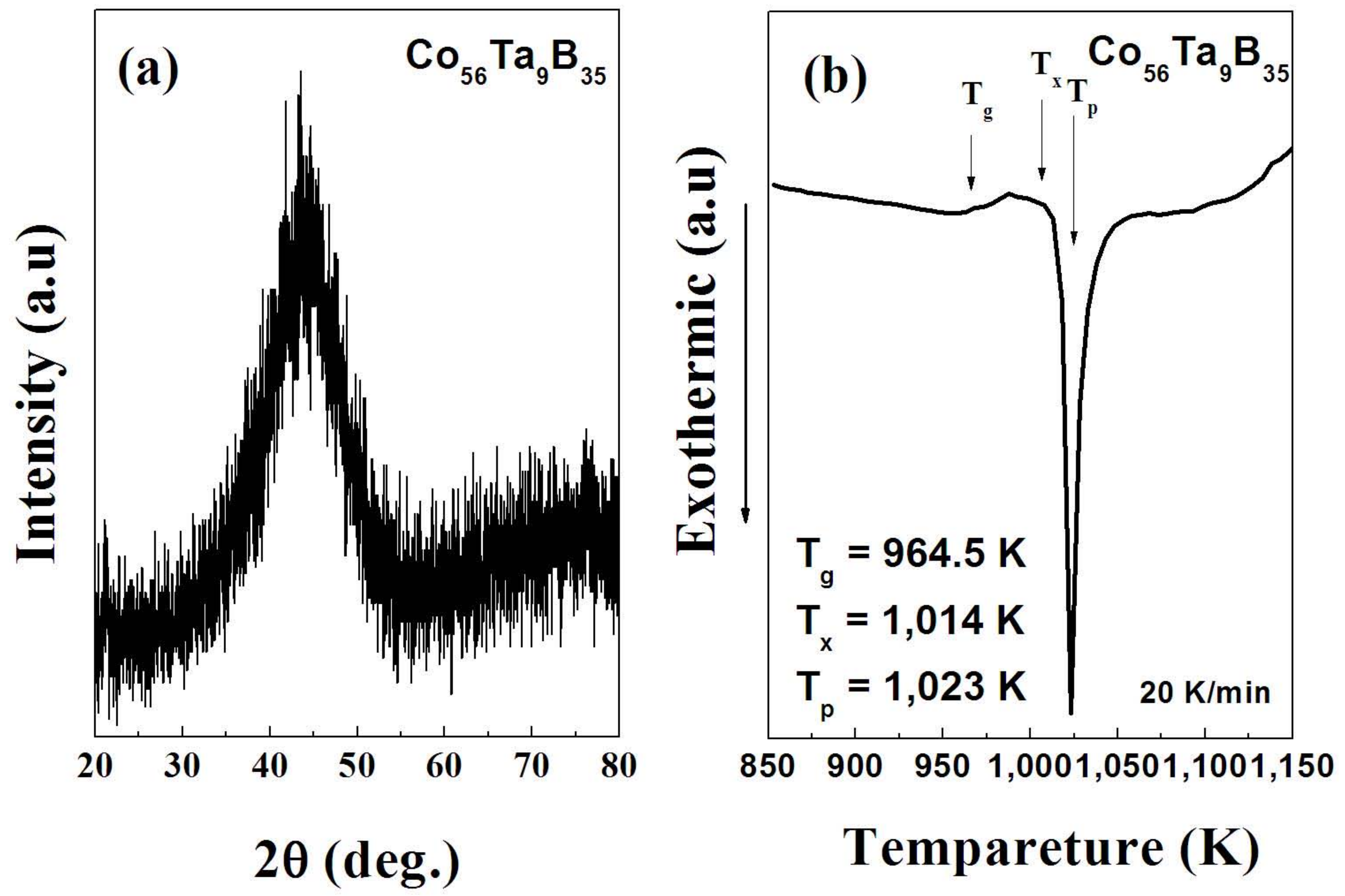


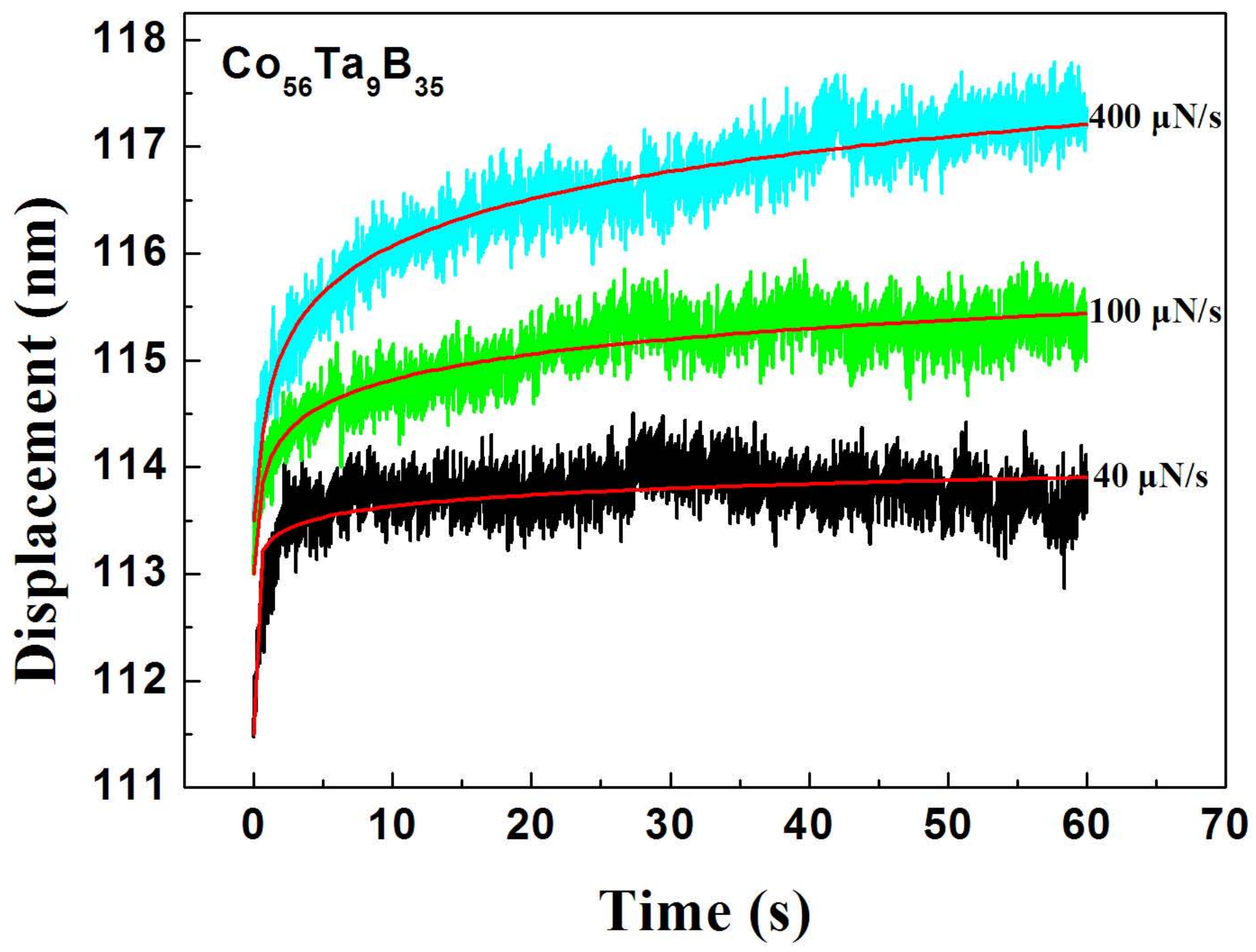



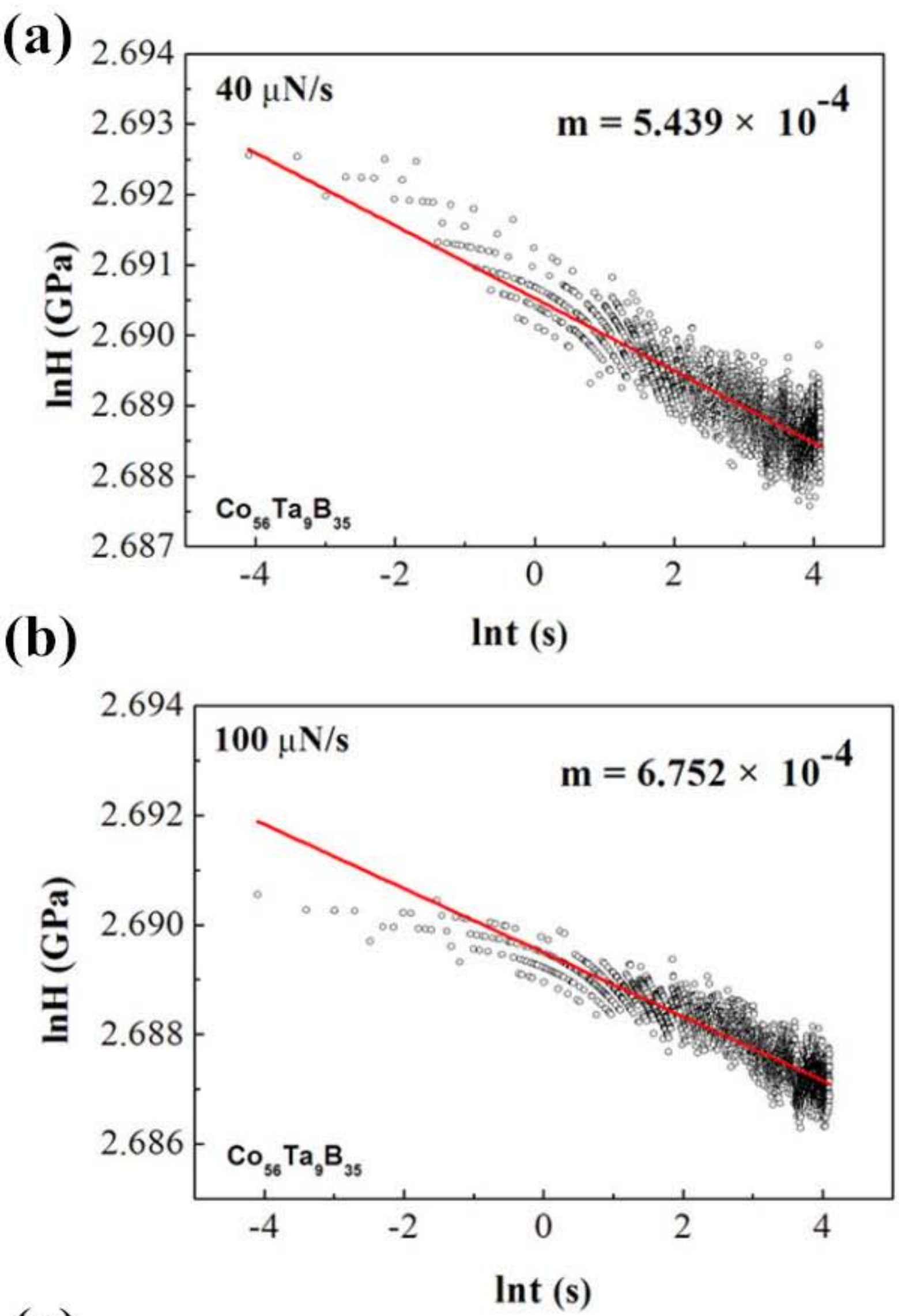

(c)

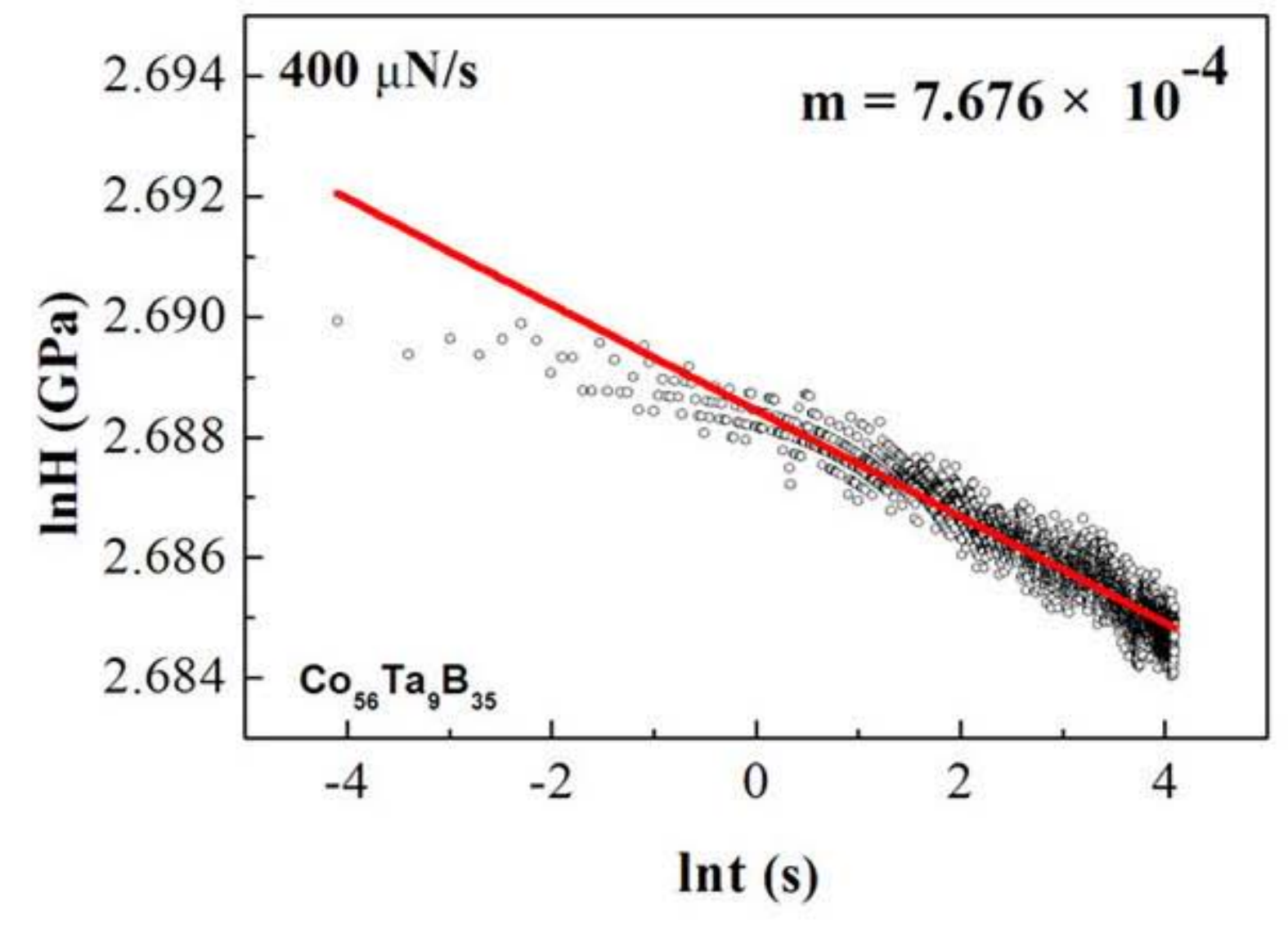


Table 1 Creep displacement and rate of ribbons at different loading rates

\begin{tabular}{lcc}
\hline Load rate $(\mu \mathrm{N} / \mathrm{s})$ & Creep displacement $(\mathrm{nm})$ & Creep rate, $\varepsilon_{\mathrm{s}}\left(\mathrm{nm} \cdot \mathrm{s}^{-1}\right)$ \\
\hline 400 & 3 & $2.40 \times 10^{-2}$ \\
100 & 2 & $1.11 \times 10^{-2}$ \\
40 & 1.5 & $0.53 \times 10^{-2}$ \\
\hline
\end{tabular}

